World Maritime University

The Maritime Commons: Digital Repository of the World Maritime University

\title{
MAAP Transition from ISO 9001:2015 to ISO 21001:2018 the new quality standard in education organization
}

\author{
Eduardo Ma R. Santos \\ Maritime Academy of Asia and the Pacific \\ Michael A. Amon \\ Maritime Academy of Asia and the Pacific
}

Follow this and additional works at: https://commons.wmu.se/imla2021

Part of the Education Commons

\section{Recommended Citation}

Santos, E. M. R..\& Amon, M.A. (2021). MAAP transition from ISO 9001:2015 to ISO 21001:2018: the new quality standard in education organization. In Pazaver, A., Manuel, M. E., Bolmsten, J., Kitada, M., Bartuseviciene, I. (Eds.), Proceedings of the International Maritime Lecturers' Association. Seas of transition: setting a course for the future (pp.80-89). World Maritime University. http://dx.doi.org/ 10.21677/imla2021.08

This Paper is brought to you courtesy of Maritime Commons. Open Access items may be downloaded for noncommercial, fair use academic purposes. No items may be hosted on another server or web site without express written permission from the World Maritime University. For more information, please contact library@wmu.se. 
http://dx.doi.org/10.21677/imla2021.08

\title{
MAAP transition from ISO 9001:2015 to ISO 21001:2018 the new quality standard in education organization
}

\author{
VADM Eduardo Ma R Santos AFP (Ret.) \\ President, Maritime Academy of Asia and the Pacific, Kamaya Pt., Mariveles, Bataan, \\ Philippines, emrs_66@yahoo.com
}

\section{Michael A. Amon, MEM}

Quality Management Representative, Maritime Academy of Asia and the Pacific, Kamaya Pt., Mariveles, Bataan, Philippines maamon@maap.edu.ph or amon.mike@gmail.com

\begin{abstract}
Sustainable success has become an ever-more-important future goal in all industries but challenges arise from the advent of fourth industrial revolution and revisions of national and international regulations directly affect the shipping industry trickling down to the Maritime Education and Training Institutions (METI). Thus, a metamorphosis of standards for a maritime school like the Maritime Academy of Asia and the Pacific (MAAP) transitioning to a more tailor-fit Quality Standards is inevitable to manage the changes in educational organizations. ISO 21001:2018 has been published in oder to replace IWA 2:2007. This prompted the Academy to evolve from the traditional ISO 9001:2015 standard. This paper aims to discuss the STCW '78 (as amended) requirements for Quality Standard System and how the new standard in educational and training organizations complies with it. The paper shall also serve as a resource and reference for those schools that are looking for standards that can attune their management systems gearing towards safer, cleaner, and excellent shipping by having a competent seafarer through a certified Educational Organization Management System. With the vision of the academy to be the leading institution of excellence in maritime and training the Asia-Pacific region and beyond, certification with the standard is indeed a milestone and breakthrough.
\end{abstract}

Keywords: ISO 21001:2018 requirements, Educational Organization Management System, QSS

\section{Introduction}

The world has changed and is currently in the transition from traditional or so called the old normal to the new normal education system due to the overwhelming pandemic crisis that greatly affected humankind and the maritime education system. Educational organizations, leaners, and lecturers' have no choice but to adapt to a warping speed of Fourth industrial revolutions (4IR) in teaching and learning. "Characterized by a fusion of technologies that is 
blurring the lines between the physical, digital and biological spheres" (Schwab, 2016) most maritime higher education institutions have adapted the eLearning systems in its core services to sail forward in this wave of unprecedented passage. How can we maintain quality education is the next question in these challenging times? This paper shall discuss how the Maritime Academy of Asia and the Pacific have adopted not only to the rigors of the premature 4IR requirements but also to the new ISO 21001:2018 requirements from the generic ISO 9001:2015. As the world has traversed to the new era of education, MAAP has navigated to the waters where educational organizations should chart its course overcoming the challenge of the worldwide crisis at hand. This paper can be a resource of hope and a framework for learners, educational organizations, and interested parties to determine what education quality standard system is tailor-fit for them may it be pandemic or not.

\section{Methods}

This paper shall use historical research methods that involve studying, understanding and interpreting past events related to ISO 9001:2015 and ISO 21001:2018 to reach insights or conclusions about occurrences. This also entails compiling and presenting factual information and emphasis on the interpretation of the information.

Furthermore, a look back on how MAAP has transitioned to the new standard amidst the plight of world changing event with both primary and secondary sources that may came from eyewitness reports and original documents, as a description of an event by someone other than an eyewitness, or a textbook author's explanation of an event or theory. Our advantage in this research is the authors and the organization are the main eyewitness of this historic certification to the new standard. This brings more credence to this paper serving as a primary source for other researchers.

With this method the paper "attempts to systematically recapture the complex nuances, the people, meanings, events, and even ideas of the past that have influenced and shaped the present". (Berg \& Lune, 2012, p. 305)

\section{Statement of the Problem}

Since 1984 to the present the majority of education has been certified to ISO 9001 standard, which covers quality and customer satisfaction. During this more than three decades of adherence, debates and interpretation dysfunctions have risen among the non-manufacturing organizations like the maritime education sector. In 2003 and 2007 ISO tried to resolve this issue by providing guidance for a quality management system in educational organizations called International Working Agreement (IWA) 2. Unfortunately, the guidelines contained within IWA 2:2007 and are not intended for use in contracts for conformity assessment or for certification.

With the publication of ISO 21001:2018, a certifiable standard for educational organization, the question is MAAP going to transition to this standard or do schools need to transition? What are the benefits of the certification this ISO 21001 from ISO 9001? When can the 
transition be done? Is the transition cost effective for schools? How can MAAP transition in the midst of the pandemic crisis? These are the questions and problems that this paper aims to resolve and provide historical accounts for others to follow and learn from.

\section{Review of Related Literature}

\section{Quality Control Background}

Long before the formal publication of ISO 9001, a known American physicist, engineer and statistician named Walter Shewhart, published his book Economic Control of Quality of Manufactured Product in 1931. Since then, he has been recognized as the father of statistical quality control and grandfather of Total Quality Management. He also created the Shewhart Cycle or PDSA (plan, do, study, act) cycle, the scientific method for learning through action as well as observation.

He worked with the well-known William Edwards Deming during World War II regarding productivity. W. Edward Deming championed Shewhart's ideas in Japan after the war and has been credited with the PLAN-DO-CHEK-ACT (PDCA) Cycle, known today as Deming's Cycle and still used as ISO 9001 key foundation and framework.

With great contributions from these quality trailblazers in quality control, Joseph Juran in 1954 focused on managing for quality and started Quality Management Courses in Japan. Widely credited with adding the human dimension to quality management, his contributions include the Pareto principle and Juran's Trilogy consisting of quality, planning, quality control and quality improvement which are still integrated in the current ISO 9001 requirements.

\section{ISO 9001 Brief History}

Rooted in US and UK standards of military defense procurement and manufacturing organizations released their own quality management standards. The UK's Ministry of Defense drove BSI to publish the very first quality management standard known as BS 5750 which specified management of manufacturing processes.

According to Taormina (2019) after World War II devastation, many aspects of business were incompatible from country to country as treaties advanced and nations were rebuilt. A single standard was then a necessity as the International Organization for Standardization was contracted to create a non-binding quality standard.

The first ISO 9001 was published in 1987 following the BS 5750 structure created by Technical Committee 176 (ISO/TC 176) formed in 1979 the has three certification parts as follows:

- ISO 9001 - for organizations that conducted design, production and servicing.

- ISO 9002 - for production and servicing companies that did not do design.

- ISO 9003 - for engaged in testing and distribution.

Early practitioners created the motto "Write down what you do, do what you write down, and make sure you are doing it" as the basic essence of the standard. "Write down what you do" refers to documenting the processes and their interactions within your organization. "Do what 
you write down" is taking actions written to realize your products and services and yield the desired outcomes. "Make sure you are doing it" refers to what we know today as QMS auditing.

The governmental bodies that controlled their version/translation of the standard certainly did not want to take on a policing function. That led to the evolution of certification organizations. Early on, agencies such as the American Bureau of Shipping (ABS) and Det Norske Veritas (DNV) added ISO 9000 certification services to their core businesses of certifying sailing vessels. The national accreditation bodies created a credentialing system for the certification companies to audit and grant certificates of conformance to individual organizations that demonstrated compliance with the standard.

From that beginning, the processes of desk audit, initial certification, periodic surveillance audits, three-year recertification and transition certification evolved into the current formal conformance process. The outcome of the TC 176 continual improvement process led to the following revisions:

1994. The first revision emphasized preventive action and made a first attempt at slowing down the documentation paper mill.

2000. The second revision was a complete rewrite and did away with the three separate standards. It focused on process management instead of reactive quality assurance and quality control. It placed a higher burden on senior management to integrate quality management into business management.

2008. This revision introduced clarifications from the ongoing work of TC 176 and began harmonization with ISO 14001:2004.

2015. Another complete rewrite of the standard, this version introduced a new era of Quality Management Systems. It suggested replacing preventive action with risk-based thinking. Further, it created a focus on business performance instead of quality metrics and greatly streamlined the required documentation.

\section{Brief ISO 21001 History}

Due to the specificity of the education sector making it different from manufacturing and other services sector activities, ISO published the IWA 2:2003 Guidelines for the application of ISO 9001:2000 in education. These guidelines were written by a group that included education experts along with experts representing national organizations for standardization (El Abbadi et al.,2013), however these guidelines are not intended for use in contracts for compliance assessments or for certification. Unfortunately, the application of ISO 9001 in Higher Education has been generically limited to the institution's services and not their core functions, namely teaching and learning (Rosa et al., 2016).

It was argued then that the idea of the student as a customer can lead to a damaging commodification of learning knowledge and the service that the schools and university provides. For ISO 9001 a customer focus is a quality management principle that has many negative connotations and is widely misunderstood by the education community. 
According to Cuthbert (2010) the commodification and the rise of academic capitalism encourages a utilitarian instrumentalism that distances the student from the deep learning and personal growth that most people believe is the most valuable part of the university experience for students, and is also the best way for universities to meet their broader social responsibilities.

The IWA 2:2007, the upgraded version of the guidelines was withdrawn in 2013 that prompted the set up of a project committee in 2014 to draft a new standard specifically dedicated to educational organizations. The project committee was given a wide mandate to consider any and all factors which have a bearing on the operation of educational organizations (Camilleri, 2017). Within the framework of WG1 of the project committee, 140 experts from 34 countries have prepared 9 iterative drafts of a standard over 10 meetings.

Finally in 2018 the ISO published 21001 standard that specifies requirements for a management system for educational organizations (EOMS) when such an organization:

a) needs to demonstrate its ability to support the acquisition and development of competence through teaching, learning or research;

b) aims to enhance satisfaction of learners, other beneficiaries and staff through the effective application of its EOMS, including processes for improvement of the system and assurance of conformity to the requirements of learners and other beneficiaries.

\section{Discussion}

\section{MAAP QMS History}

Since 1999, when MAAP started its operation, the certification to ISO 9001 was number one priority not only because of its benefits but it was a regulatory requirement for Maritime Higher Education to have our program permit to operate going to recognition. As it was said by the late Capt. Gregorio Oca, "It's not the quantity we are after but the quality of education for future Filipino seafarer", it has been the beacon on inspiration in establishing our vision and mission to provide quality Maritime Education and Training (MET) and be the leading institution of excellence in the Asia-Pacific region and beyond.

On June 22, 2000, DNV country manager Mr. Antonio Leosala, awarded the certification ISO 9001:1994 version to the Academy and DNV Rules for Maritime Academy. After a year, certification on DNV Rules for Training Center on March 8, 2001. Understanding that the standard was designed after manufacturing, the institution has undergone to adapt the certification to MET standards with emphasis on design and development and course delivery requirements. As ISO evolved the academy also adapted ISO 9001:2000 version certification from elemental approach into process-based approach.

MAAP continued to understand the unique operation of an educational institution that is why it shifted its standards from DNV Rules to PSB 100:2002 QMET standards because the standard does not only focus on MET but STCW '78 as amended requirements. Strides to comply with PSB 100:2002 standard paid off when on March 13, 2006 EMSA started to audit maritime schools. During the audit, according to Dr. Veiga, MAAP's Quality System was very 
impressive for there were no major deviations or problems during the course of the assessment. Formal certification to PSB 100:2002 was received on December 20. 2006 with Mr. Subir Mukerji as lead auditor.

Come ISO 9001:2008 version with minute update, MAAP was certified on June 8, 2009. With the major revision to ISO 9001:2015, MAAP was the first MEI to be certified by DNV in the Philippines adopting Risk-based management. With revision of ISO 9001 the PSB standard cannot keep up to the update leaving our standards in MET outdated.

A year before the publication of ISO 21001 during our celebration of Quality Day, in 2017 we learned about the coming new standards and announced that the academy will pursue this certification.

\section{MAAP Transition}

While awaiting the publication of the new standards, the drafts have been studied already by the Quality Assurance Department. Upon publication of the new standard last May 2018 by ISO/TC 232 Education and learning services Technical Committee, Vice-President Felix Oca had purchased from ISO the ISO 21001:2018 standards that started the formal transition to Educational Organization Management.

Based on the Deming Cycle, we have planned the certification transition in our Annual Quality Plan and revised the quality manual which we now call Educational Quality Standard System (EQSS) to cover standard documentation requirements. Then we start the DO with orientation covering 7.3 Awareness and 7.1.6 Organizational knowledge requirements to jumpstart the transition. After the manual had been revised, we conducted 9.2 Internal Audit and 9.3 Management review to comply with requirements as part of the CHEK and ACT cycle part.

DNV-GL as one of the leading certification body in the maritime industry have been contracted to certify the school and long-time management system partner. Starting with Stage 1 Desktop Audit we have sent relevant documents resulting to zero major and major nonconformities. There were two (2) Observations and one (1) finding during the desktop audit concerns 4.3 Scope, 5.2 Policy, and 9.3.2 Management Review Input.

Passing the certification stage 1 was a breeze; however, when the actual certification audit was scheduled last March 16-17, 2020, the community quarantine for Luzon and Manila was announced by President Duterte. This means we had to reschedule on week 13 dated March 23-27, 2020 for we could not pursue an on-site audit due to travel restrictions. Unfortunately, we all know the situation escalated to a worldwide pandemic and Enhanced Community Quarantine was enforced and the proposed new schedule was further moved.

On May 1, 2020, finally DNV sent an email stating that Accreditation Bodies have set out rules to make remote audits for certain industries possible. Hence, another transition milestone for MAAP has been etched to its QMET journey to have its first remote certification audit scheduled last May 13-15, 2020. 
A taste of the 4IR has been laid to the MAAP table and it was a learning experience for all parties to participate in a remote audit. With minor internet lags all went well with Ms. Marita Bayon as Lead Auditor having zero (0) major and minor nonconformities, two (2) observations, and four (4) opportunities for improvement. Indeed, in every difficulty lies an opportunity as the saying goes.

Requirements that need to be improved on were as follows:

- 6.1 Action to address risk and opportunities - pandemic related

- 7.1.2.2 - commitment to social responsibilities, ethics as input to management review

- 8.4 - Control of externally provided processes, products and services

- 8.5.5 - Protection and transparency of learners' data

- 9.1.2 - Satisfaction of learners, other beneficiaries and staff

- 9.3.2 - Management review inputs

\section{Transition Reflections}

Looking back at MAAP management system history it was evident that the institution has understood that ISO 9001 standard alone will not suffice to provide QMET for the learners and other beneficiaries. The Academy has always been subscribing to standards that focus on education and training as shown in Figure 1. From having three standards, then two standards and now one standard transition has been one of the key highlights of the transitions.
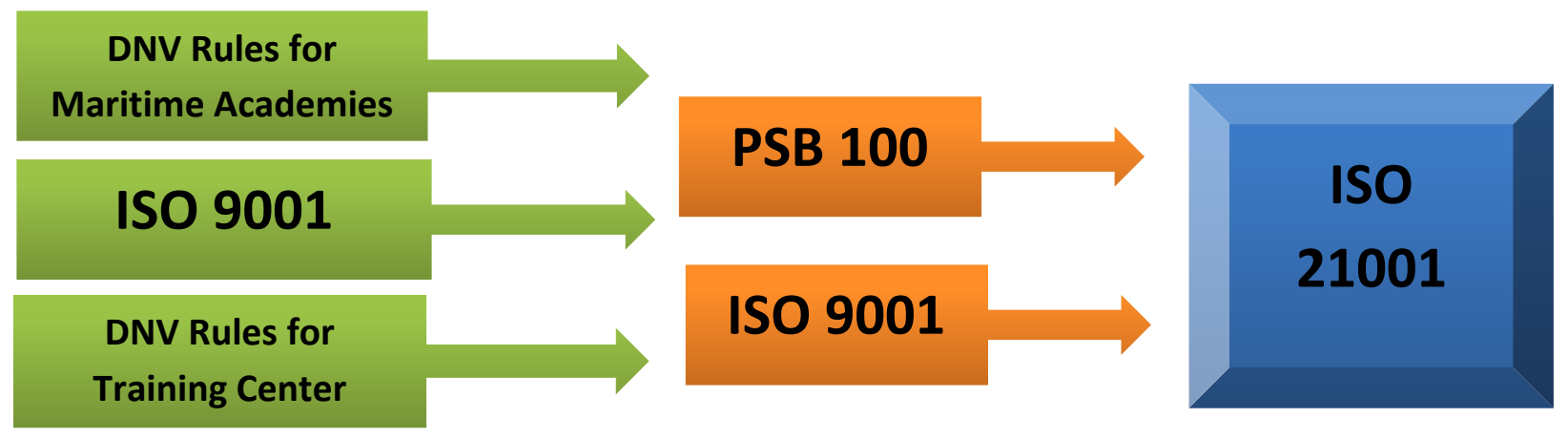

Unlike the ISO 9001, which has a primary focus “... to consistently provide products and services that meet customer and applicable statutory and regulatory requirements ..." As stated in Clause 1.a of ISO 9001:2015, the ISO 21001:2018 navigates its course leaning toward competence as stated in 1.a Scope "... to demonstrate its ability to support the acquisition and development of competence through teaching, learning or research; “.

Furthermore, according STCW '78 as mended Article 1.2 “... The Parties to promulgate all laws, decrees, orders and regulations and to take other stipe which may be necessary to give the Convention full and complete effect, ..., seafarer on board ships are qualified and fit for their duties.", refers to seafarers competence. On June 7, 2019, the Philippine's Maritime Industry Authority (MARINA) and Commission on Higher Education (CHED) issued a Joint CHED-MARINA Memorandum Circular No. 1, Policies, Standards and Guidelines (PSG) for the Bachelor of Science in Marine Transportation and Bachelor of Science in Marine 
Engineering Programs. In Article I Section 1. Rational and Background stated that. “... this PSG implements the shift to learning competency-based standards (CBS)/outcome-based education. (OBE)"

Therefore, when we analyze STCW, ISO 21001 and CHED-MARINA joint memorandum circulars their intended outcome boils down to COMPETENCE. With this transition in the education system of content-based into the CBS/OBE framework the transition to ISO 21001 indeed is responsive to the times and not force-fit like the ISO 9001.

Key benefits that the academy have gained with transition to ISO 21001 were as follows:

1. Cost effective certification - having to pay for three and two certifications before now we fund savings since we only have to pay for one certification.

2. Tailor-made EQSS - no more wrong interpretation of ISO 9001 for service organization all requirements in the standard are fit for an educational organization such as MAAP

3. $\mathrm{CBS} / \mathrm{OBE}$ compliance - Shifting to the standard is like four birds in one stone that the academy has adhered to STCW, ISO, and CHED-MARINA as the national and international bodies implementing statutory and regulatory standards.

4. Two-in-one Standards compliance - ISO 21001 as partially framed from ISO 9001 the institution has the benefits of a risk-based educational organization management system a combination of two standards

5. 4IR certification and operations - the school have experienced the applied fusion of physical, digital, and biological during the remote certification audit and managing the academy's EQSS and MET operations.

\section{After ISO 21001 Certification}

After certification to ISO 21001 it was worth mentioning that the academy has continued operations in spite of the global lockdowns. More sponsors are eager to get scholars from the school. Other maritime schools have benchmarked on MAAP operations and admission. Cloud-based simulation has been initiated with Kongsberg. Full development and implementation of our Learning Management System. An online Assessment system was implemented called Student Examination and Assessment System. Most of the office processes have been made online and digital. Classrooms have adopted flexible mode synchronous online sessions using Google Meet and asynchronous using Google Classroom and LMS.

Accolades from the industry partner, Mr. Francesco Garguilo, IMEC Chief Executive Officer, officially lauded MAAP for ensuring that its cadetship program in the Philippines continued in spite of the challenges posed by the pandemic during an interview with Marino World's Maritime Viewpoint last February 2020. Just recently MAAP bags the $2^{\text {nd }}$ Prize winner on CHED and University of the Philippines Open University during the $1^{\text {st }}$ Philippine Higher Education Internationalization Award last May 19, 2021 marks that our Transition was indeed value-adding to the organization. Furthermore, the bottom line is our graduates' performance on the National Licensure Examination by MARINA with the recent results MAAP have Deck OIC 98\% passing rate and Engine OIC 85\% passing rate exemplifies and effective EQSS transition to ISO 21001. 


\section{Conclusion}

MAAP and other maritime schools or training centers need to use the correct management tool to provide quality education and training to learners to develop their competency needed by the industry to ensure safety of life, property, and environment at sea for sustainable shipping industry. With MAAP trailblazing the transition from manufacturing-based standard 9001 into educational organization standard fit standard 21001 have paved the way for others to follow. In this era of passage in a new mode of teaching and learning brought about by the pandemic and turbo boosted the 4IR, the management system is also another venue that education and training must evolve itself just like using a rudder moving steadily forward for ships instead of a fin used for cars. The benefits of transition were very evident in terms of cost, competence focus, risk-based thinking, and flexibility to adapt to the ever altering fabric of history. The best time to transition is now because even if the pandemic ends, the new standard and practice in the education system may be the norm of the future of MASS, IA, robotics, internet of things, cybersecurity and many more. As the old saying goes, change is the only constant thing in this world. We need a metamorphosis to a new and better system for our learners and other beneficiaries using ISO 21001 as our management system is fully aligned to the nature of an educational organization.

\section{Recommendations}

1. Inspire by being a benchmark school and assist other education and training organizations to convert their management system into ISO 21001 for them to benefit from guidance of international standards at single cost by promoting national MET associations like PAMI and PAMTCI.

2. MAAP to further pursue to other education quality standard accreditation at the national level such as PACUCOA level IV, Philippine Quality Awards, Center of Excellence, Asia Pacific Accreditation, NI and IMAREST accreditation and other relevant standard that will level up the academy's systems and standard at par with its international peers.

3. To develop an online ISO 21001 awareness course for other schools and other beneficiaries to appreciate the value-adding benefits to the new standard overcoming fear and lack of understanding on the new standard.

4. Innovation Team to come up with other recommendations and projects that will propel the academy MET systems ready for the next wave of maritime industry global maritime profession competency requirements and demands.

5. Full automation of MAAP EQSS to include strategic planning, risk management, internal audit, feedback system, program/course monitoring and review, and management review inputs that will fast track analysis and report generation of PLANS, ACTIONS(DO), CHECK, ACT cycle of ISO 21001. 


\section{References}

Berg, B.L. \& Lune, H. (2012). Qualitative Research Methods for the Social Sciences, $8^{\text {th }}$ Edition. Pearson.

Camilleri, A. (2017). Standardizing management systems for educational organizations: Implications for European higher education. 12 ${ }^{\text {th }}$ European Quality Assurance Forum, Riga, Latvia, 23-25 November 2017.

Cuthbert, R. (2010). Students as customers. Higher Education Review, 42(3), 3-25.

El Abbadi, L., Bouayad, A., \& Lamrini, M. (2013). ISO 9001 and the Field of Higher Education: Proposal for an Update of the IWA 2 Guidelines. Quality Approaches in Higher Education, 4(2), 14-19.

ISO (2018). ISO 21001 Educational organizations- Management system for educational organizations - Requirements with guidance and use (First Edition 2018-05). ISO, ISO Copyright Office, Published in Switzerland

IMO (2017). STCW Including 2010 Manila Amendments STCW Convention and STCW Code (2017 Edition). International Maritime Organization. 4 Albert Embankment, London SE1 7SR

ISO (2015). ISO 9001 Quality Management Systems - Requirements (Fifth Edition 2015-0915). ISO copyright Office, Published in Switzerland

JCMMC (2019). Policies, Standards, and Guidelines for the Bachelor of Science in Maritime Transportation and Bachelor of Science in Marine Engineering - JCMMC No. 1 Series of 2019. 14 June 2019 Business Mirror

DNV-GL (2020). Stage 1 Audit Report Maritime Academy of Asia and the Pacific - Project Number - PRJN-180861-2020-MSC-PHL. DNV-GL Business Assurance.

DNV-GL (2020). Initial Audit Maritime Academy of Asisa and the Pacific - PRJC-1414962009-MSC-PHL. DNV-GL Business Assurance.

Rosa, M. J., Sarrico, C. S., Tavares, O., \& Amaral, A. (2016). Cross-Border Higher Education and Quality Assurance: Commerce, the Services Directive and Governing Higher Education. Springer.

Taormina, T. (2019). The history and future of the ISO 9000 series of standards. https://advisera.com/9001academy/blog/2019/04/15/history-of-the-iso-9000-series-ofstandards-and-what-to-expect-next/ 